\title{
The earthquake of 250 a.d. in Augusta Raurica, A real event with a 3D site-effect?
}

\section{Journal Article}

\section{Author(s):}

Fäh, Donat; Steimen, Sibylle; Oprsal, Ivo; Ripperger, Johannes; Wössner, Jochen; Schatzmann, Regula; Kästli, Philipp; Spottke, Ina; Huggenberger, Peter

\section{Publication date:}

2006

\section{Permanent link:}

https://doi.org/10.3929/ethz-b-000022610

\section{Rights / license:}

In Copyright - Non-Commercial Use Permitted

\section{Originally published in:}

Journal of Seismology 10(4), https://doi.org/10.1007/s10950-006-9031-1 


\title{
The earthquake of 250 A.D. in Augusta Raurica, A real event with a 3D site-effect?
}

\author{
Donat Fäh • Sibylle Steimen • Ivo Oprsal • \\ Johannes Ripperger • Jochen Wössner • \\ Regula Schatzmann • Philipp Kästli • \\ Ina Spottke • Peter Huggenberger
}

Received: 15 February 2005 / Accepted: 2 June 2006 / Published online: 7 November 2006

(C) Springer Science + Business Media B.V. 2006

\begin{abstract}
The Roman city Augusta Raurica is located East of Basel, Switzerland. One important topic of the city's history concerns the hypothesis of an earthquake striking the city in the middle of the third century A.D. This idea had been formulated according to archaeological features and findings, but had not been tested so far. A selection of the archaeological features were reviewed and dated in order to test the hypothesis of a single event. However, archaeological investigations do not draw a conclusive picture; it could not be proven that all features of possible destruction date to the same event. Detailed seismological investigations were performed. These included geological and geotechnical mapping of the unconsolidated sediments. Important parameters such as the thickness and composition of the unconsolidated sediments, the terrain topography and the topography of the bedrock surface were mapped. Ambient vibration $\mathrm{H} / \mathrm{V}$ measurements provided the
\end{abstract}

D. Fäh $(\bowtie) \cdot$ S. Steimen · I. Oprsal · J. Ripperger •

J. Wössner $\cdot$ P. Kästli

Swiss Seismological Service,

ETH Hoenggerberg,

8093 Zürich, Switzerland

e-mail: faeh@sed.ethz.ch

R. Schatzmann

Roman Museum of Augusta Raurica,

Augusta Raurica, Switzerland

I. Spottke $\cdot$ P. Huggenberger

Earth Sciences, University of Basel,

Basel, Switzerland fundamental frequency of resonance for the unconsolidated sediments. The velocity of shear waves traveling through sediments is the controlling parameter for amplification of seismic waves. This material property is estimated using the relation between the ellipticity of the fundamental mode Rayleigh wave and the $\mathrm{H} / \mathrm{V}$ curve. From all information we compiled a threedimensional model of the surface geology. This model is used to simulate earthquake ground motion and amplification effects in the city, and to map the variability of the amplification. In the part of the city where possible earthquake damage was recognized, amplification occurs in the frequency band of building resonance $(2-8 \mathrm{~Hz})$. In the other part of the city amplification occurs much above the building's resonance. From 1D modelling we estimate a difference in spectral amplification of about a factor of 2.5 to 3 between the two parts of the city. This corresponds approximately to a difference in macroseismic intensity of one unit. 3D modelling showed a large variability of ground motion within very close distance in the part of the city where possible earthquake damage was recognized. The maximum amplification reaches values up to a factor of nine, which is due to 3D effects and the choice of using vertically incident waves. Finally, all paleoseismological findings in the area of Basel were reviewed in order to find indications of a large event in the time-period of interest. Paleoseismological findings provide no hints to a large earthquake in the third century. If we assume that an earthquake caused at least part of the identified damage in Augusta Raurica, 
we have to assign to this event a magnitude $\mathrm{Mw}$ of about 6.0 or even lower, that is much smaller than the value of 6.9 that is actually in the Swiss earthquake catalogue. The earthquake source of this event must then be very close to the site of Augusta Raurica and a strong site-effect occurred in one part of the city.

Key words archaeo-seismology $\cdot$ earthquake site-effects · velocity structure $\cdot$ seismic ground motion modelling $\cdot$ Augusta Raurica $\cdot$ Switzerland

\section{Introduction}

This paper targets an important event in the history and the development of the Roman city of Augusta Raurica in the third to the first half of the fourth century A.D. This historically decisive time for the city comprises the late phase and the end of the Middle Roman Imperial Period as well as the transition to the Late Roman Period. One important topic of the city's history in this period concerns the hypothesis of an earthquake striking the city at some time in the middle of the third century. This idea was formulated on the basis of archaeological features but has so far not been fundamentally tested. The issue is addressed in an interdisciplinary approach by archaeologists and seismologists.

In order to analyse this event from a seismological point of view, detailed investigations were performed. These included geological and geophysical investigations and the measurement of the fundamental frequency of resonance of the soft sediments with ambient vibration $\mathrm{H} /$ $\mathrm{V}$ spectral ratios. From the combined information, the area was divided into five zones. Each zone has a similar geology and similar shape of the $\mathrm{H} / \mathrm{V}$ spectral ratios. In the next step, the $S$-wave velocities of the different geological units are estimated from single-station $\mathrm{H} / \mathrm{V}$ ratios, and ground motion amplifications are computed from a series of hypothetical seismic sources using 1D models at different sites. Finally 3D numerical modelling is used to show that complex resonance phenomena may cause strong amplification effects in one part of the city.

\section{The hypothesis of an earthquake in Augusta Raurica}

The event of Augusta Raurica is listed in the Earthquake Catalogue of Switzerland (ECOS02) (Fäh et al. 2003a) as a questionable earthquake with moment magnitude $\mathrm{Mw}=6.9$. Along with the Basel earthquake of 1356, this was considered to be the strongest reported event in the northern part of Switzerland (Figure 1). As will be outlined in this work, a substantial revision of the size of the event is proposed, based on paleoseismological findings in the area of Basel.

For the compilation of the earthquake catalogue ECOS02, the size estimate of the Augusta Raurica event was based on the archaeological features that are considered to be possible effects of an earthquake in the middle of the third century. Figure 2 indicates the locations of these features. These include large and smaller segments of walls that collapsed as an entire unit. Examples of possible earthquake effects are a building complex in the south of the town (Figure 3a) and features on the northwest corner of the theater (Figure 3b), fallen sections of columns, human bodies buried under parts of buildings (Figure 3c), and repairs of a partly improvised nature which may suggest that only reduced financial means were available for reconstruction. A selection of these archaeological features (e.g., fallen sections of walls, human skeletons) were reviewed and dated in order to test the hypothesis of a single event. However, the archaeological investigations do not draw a conclusive picture and it could not be proved that all features of possible destruction date to the same event (Schatzmann, unpublished). Furthermore, there may be other explanations for a number of the building damage features observed than the hypothesis that they are caused by an earthquake.

The Roman city can be divided roughly in two parts (Figure 2): the actual city center was situated in the socalled upper city (Oberstadt). Here, alongside residential and trading districts, stood the most important public buildings, such as the forum, theatre, amphitheatre and various temples and shrines. The upper city is located on a river terrace and partly lies on top of a graben structure. This part exhibits the described damages. The lower city (Unterstadt) comprised workshops for various trades and simpler residential buildings. It is built in a lower-lying part of the Rhine valley on Quaternary gravel layers (Niederterrassenschotter) of about $10 \mathrm{~m}$ thickness. Here no damage pointing to an earthquake has been found so far. In the lower city, the lack of features pointing to an earthquake may relate to the overall poorer state of preservation of building structures in the period under discussion when compared with the upper city. 


\section{Geological investigations}

The first step in our investigations included the geological and geotechnical mapping of the unconsolidated sediments. Important parameters are the thickness and composition of the unconsolidated sediments, the terrain topography and the topography of the bedrock surface. All of these parameters influence the seismic waves and are decisive for the occurrence of resonance phenomena during an earthquake. The groundwater level, which can be important for the non-linear behaviour of sediments, is at depths larger than $10 \mathrm{~m}$ below the surface or below the base of the Quaternary sediments. This parameter has therefore not been assigned a high influence on earthquake ground motion and damage.

A large amount of the geologic data is available from archives and databases of the University of Basel. An overview of the available borehole data is shown in Figure 4. Additionally, geo-electrical sounding was applied in selected parts of the area to achieve a more detailed picture of the local geology (Spottke 2002).
Augusta Raurica is located about $7 \mathrm{~km}$ to the east of the eastern Rhine Graben master fault. It is tectonically part of the Tabular Jura, which consists of a series of horst and graben structures. The upper city of Augusta Raurica is located on top of a relatively complex graben that consists of three NNE-SSW trending normal faults. The eastern fault represents the master fault of this graben. It is shown in Figure 4. The graben structure is getting thinner in thickness to the NNE, and it is composed of Keuper layers, followed in depth by Muschelkalk (limestones). Towards the river Rhine the bedrock consists of Triassic carbonate sequences of the 'Oberer Muschelkalk.' On top units of fluvial sediments, predominately gravel, have been deposited during Pleistocene times. The thickness of unconsolidated sediments varies between 20 and about $40 \mathrm{~m}$ with maximum thickness in the upper city. Subsequent erosion during late Pleistocene and Holocene times led to the formation of characteristic river terraces. The upper city is located on the upper most terrace, whereas the lower city was built on top of the lower river terrace with much smaller thickness of unconsolidated sediments (maximum $10 \mathrm{~m}$ ).
Figure 1 Known earthquakes between 250 and 2001 in Switzerland and neighbouring countries that caused damage (ECOS02, Fäh et al. 2003a). The third century Augusta Raurica event is marked with an arrow.

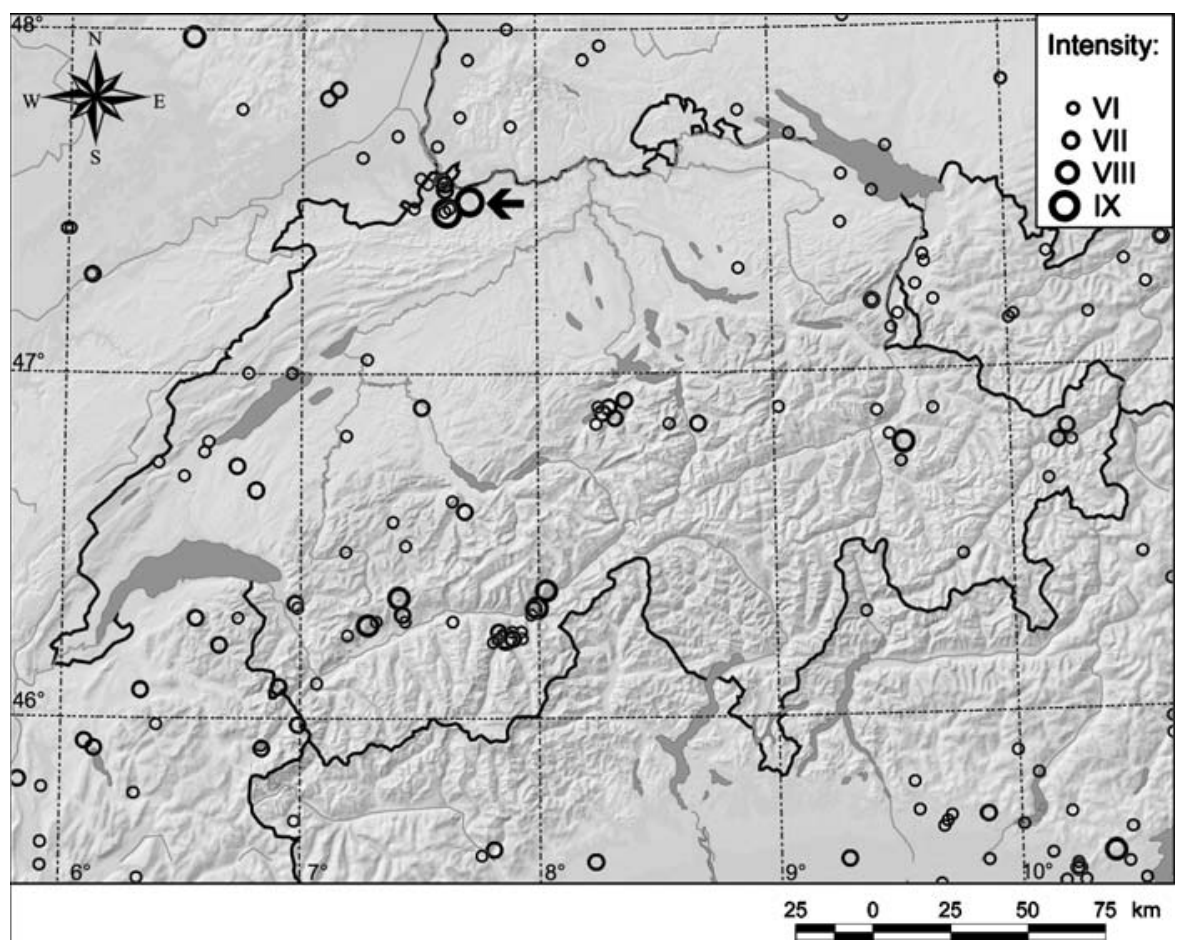




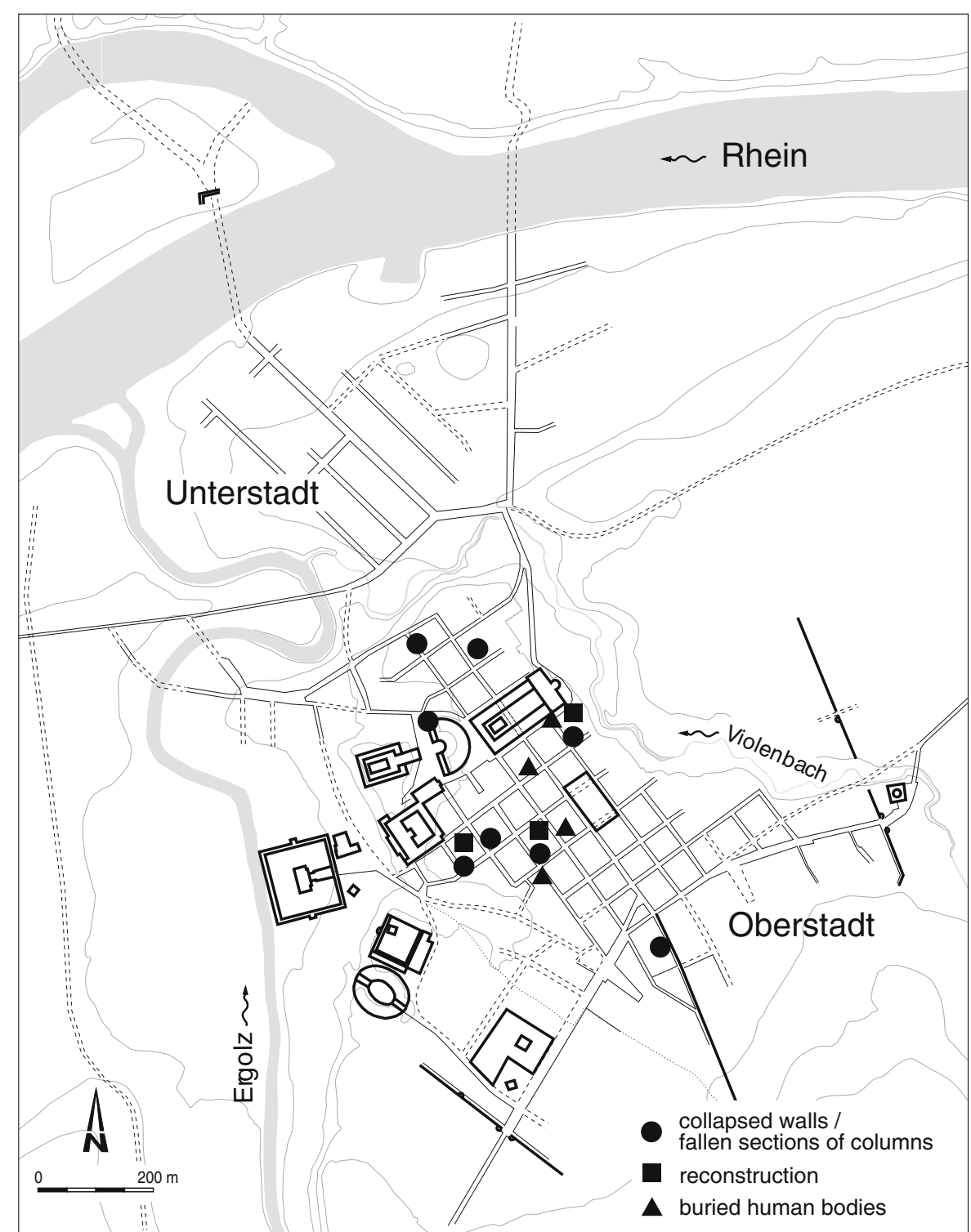

Figure 2 Overview of Augusta Raurica (from Schatzmann, not published), showing the locations of the archaeological features that are considered as indicative of an earthquake.

\section{Measurement of the fundamental frequency of resonance}

In a second step the dynamic behaviour of the unconsolidated sediments is estimated using the fundamental frequency of resonance of these sediments. This frequency can be determined utilizing ambient vibrations. For our work we use the classical $\mathrm{H} / \mathrm{V}$ method using the Fourier-transform of the signals and a frequency-time analysis (FTAN) procedure as proposed by Fäh et al. (2001). All measurements were performed using a standard procedure
(Wösser 2002; Ripperger and Fäh 2003). All ambient vibration records have been analysed and the fundamental frequency of resonance has been determined for all sites (Figure 5).

By knowing the fundamental frequency of resonance, we qualitatively know the expected amplification as function of frequency: the expected amplification is large at the fundamental frequency of resonance and significant for the frequency range above, but absent in the frequency range below about $f_{0} / 2$. The amplitude of the $\mathrm{H} / \mathrm{V}$ spectral ratio at the fundamental frequency $f_{0}$ is an indicator for the 

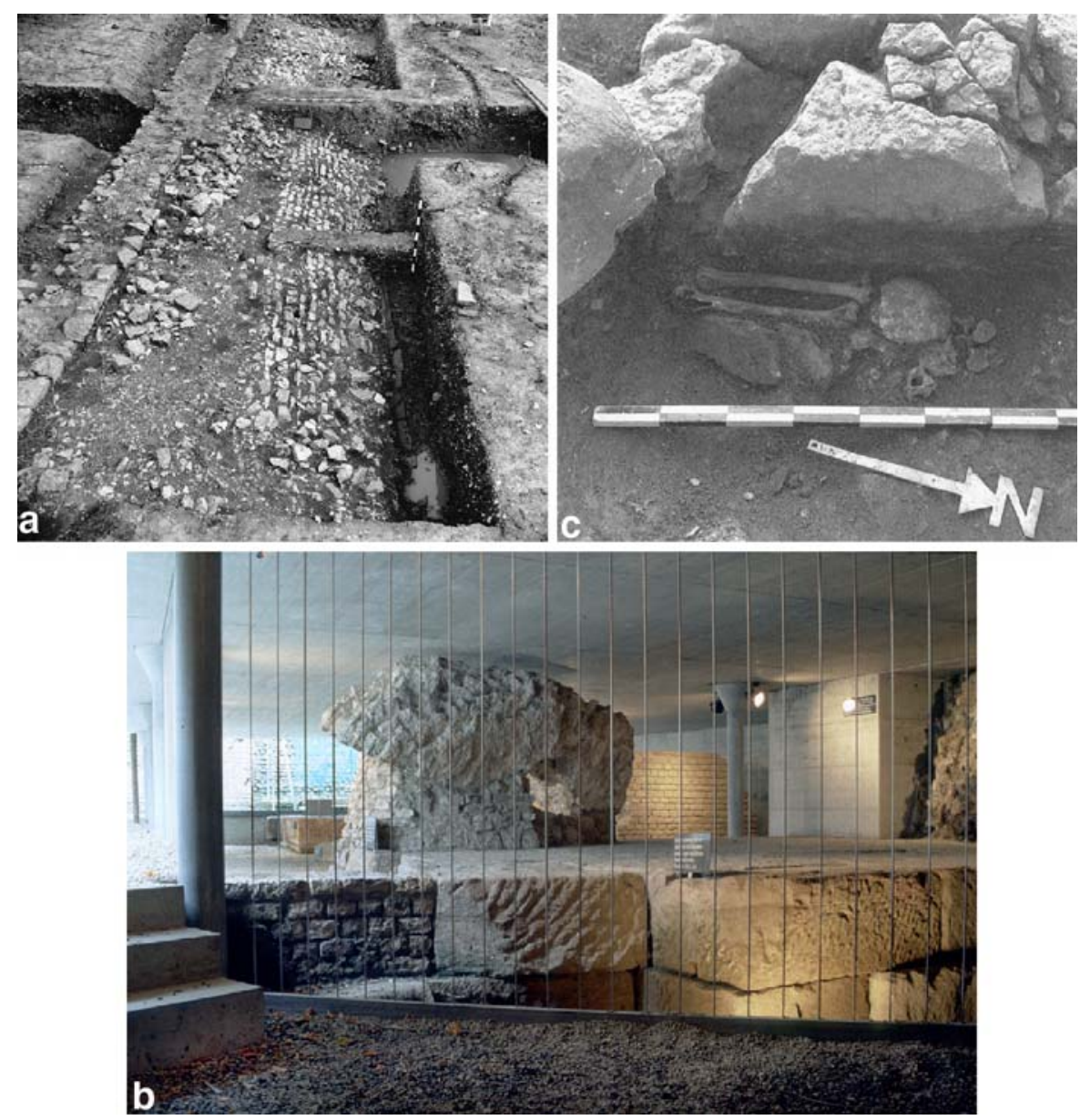

Figure 3 Examples of archaeological findings that might be due to a strong earthquake: (a) long collapsed walls (Bender 1975), (b) collapsed segment of wall by the theatre (photo:
Römerstadt Augusta Raurica), and (c) buried human bodies (Schibler and Furger 1988).
$S$-wave velocity contrast between bedrock and sediments, and provides some information on the severity of possible resonance effects during earthquakes. The higher the amplitudes the larger is the velocity contrast. However, the amplitude of the H/V ratio depends not only on the velocity contrast but also on the sourcedepth distribution and source-distance distribution. Amplitudes of the $\mathrm{H} / \mathrm{V}$ ratio therefore provide only a qualitative indicator of possible resonance effects.

$\mathrm{H} / \mathrm{V}$ spectral ratios can be considered as the fingerprint of the local structure. By comparing measurements within an area, similar $\mathrm{H} / \mathrm{V}$ curves are observed on similar local structures. Such comparison therefore allows for a zonation. Each site within one zone is expected to show similar amplification effects during earthquakes. This idea will be applied for the area in order to propose a zonation based on the shape of the observed ambient vibration $\mathrm{H} / \mathrm{V}$ spectral ratios and the geology from borehole information.

The area can be divided into several zones with similar shape of the H/V spectral ratios. The zones are given in Figure 5 and examples of $\mathrm{H} / \mathrm{V}$ spectral ratios for zone IIa (upper city) and zone IV (lower city) are given in Figure 6. The amplitudes are given in $\log 10$ scale. It can be recognized in Figure 5 that the fundamental frequency of resonance in the upper and lower city are very different, and therefore, expected amplification effects in the upper and lower city are also different. While in the upper part of the city amplification occurs in the frequency band of building resonance $(2-8 \mathrm{~Hz})$, the amplifications in the lower city occur much above the building's resonance. As a consequence, site effects play a major role in the upper city but to a lesser extent in the lower city. 


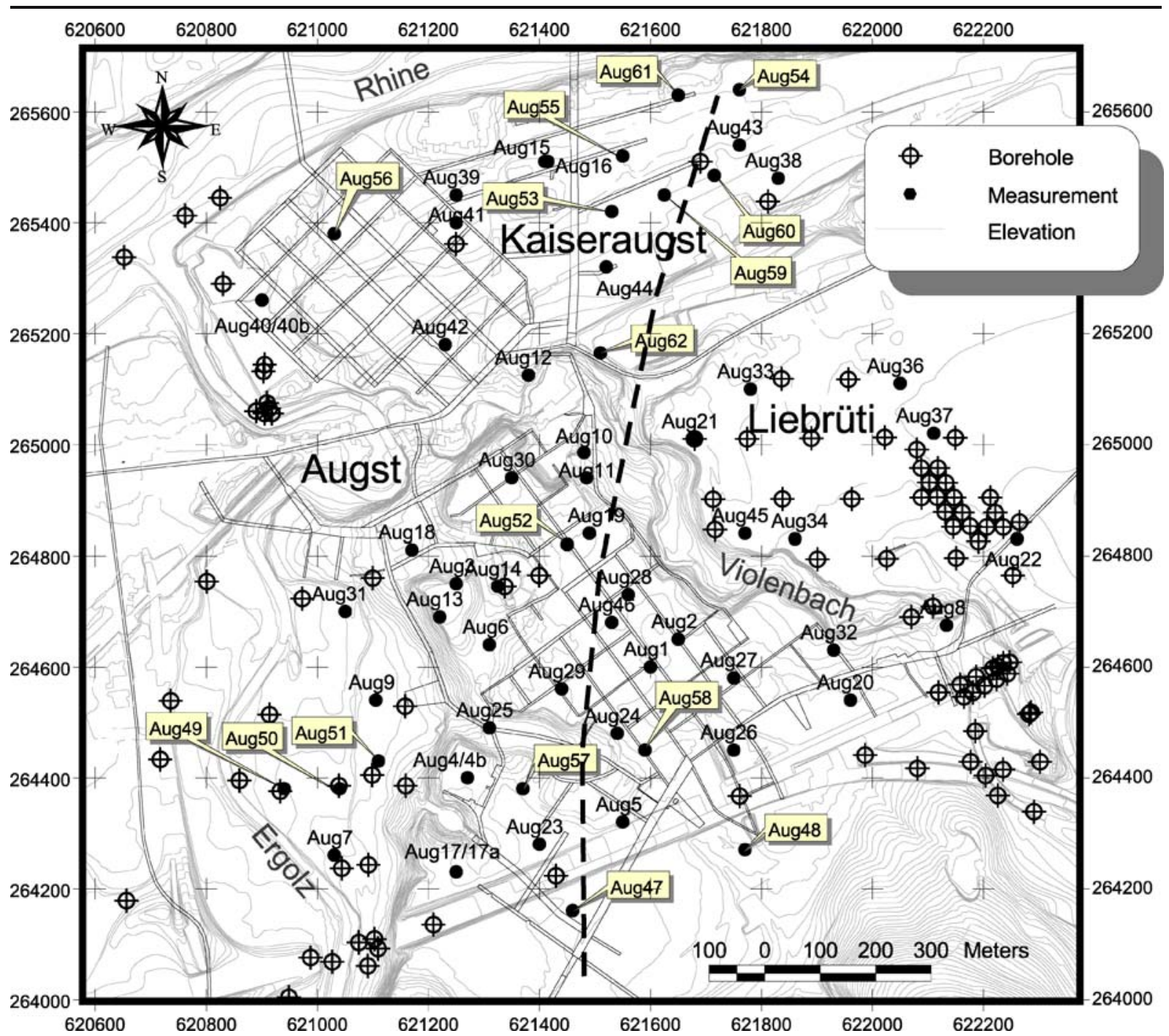

Figure 4 Overview of measurement point and borehole locations, superimposed on the elevation contours and Roman streets (black lines, partly only assumed). The approximate position of the eastern fault of the graben structure is given as a black dashed line. The coordinates are given in meters of the Swiss coordinate system.

The amplitudes of the $\mathrm{H} / \mathrm{V}$ curves close to the fundamental frequency of resonance for the upper city are smaller than for the lower city (Figure 6). Assuming the same bedrock, this feature indicates a larger average shear-wave velocity for the sites in the upper city. This can be explained by the presence of the Keuper sediments in the graben that have larger values of the shear-wave velocity than the Quaternary sediments.

\section{Estimation of shear-wave velocities}

The velocity of shear waves travelling through sediments is the controlling parameter for amplification of seismic waves. This material property can be determined by active seismic measurements like reflection or refraction seismics. But because it is not possible to use explosions or to lay out seismic profiles in the archaeological sites, another method is favoured in this project: good estimates of the shear-wave velocity can also be obtained by utilizing properties of the ambient ground vibrations. We deduce the velocity structure from the shape of the computed $\mathrm{H} / \mathrm{V}$-spectra. It is assumed that the $\mathrm{H} / \mathrm{V}$-curve around the fundamental frequency of resonance is dominated by the ellipticity of the fundamental mode Rayleigh wave (Fäh et al. 2001, 2003b). We use a genetic 


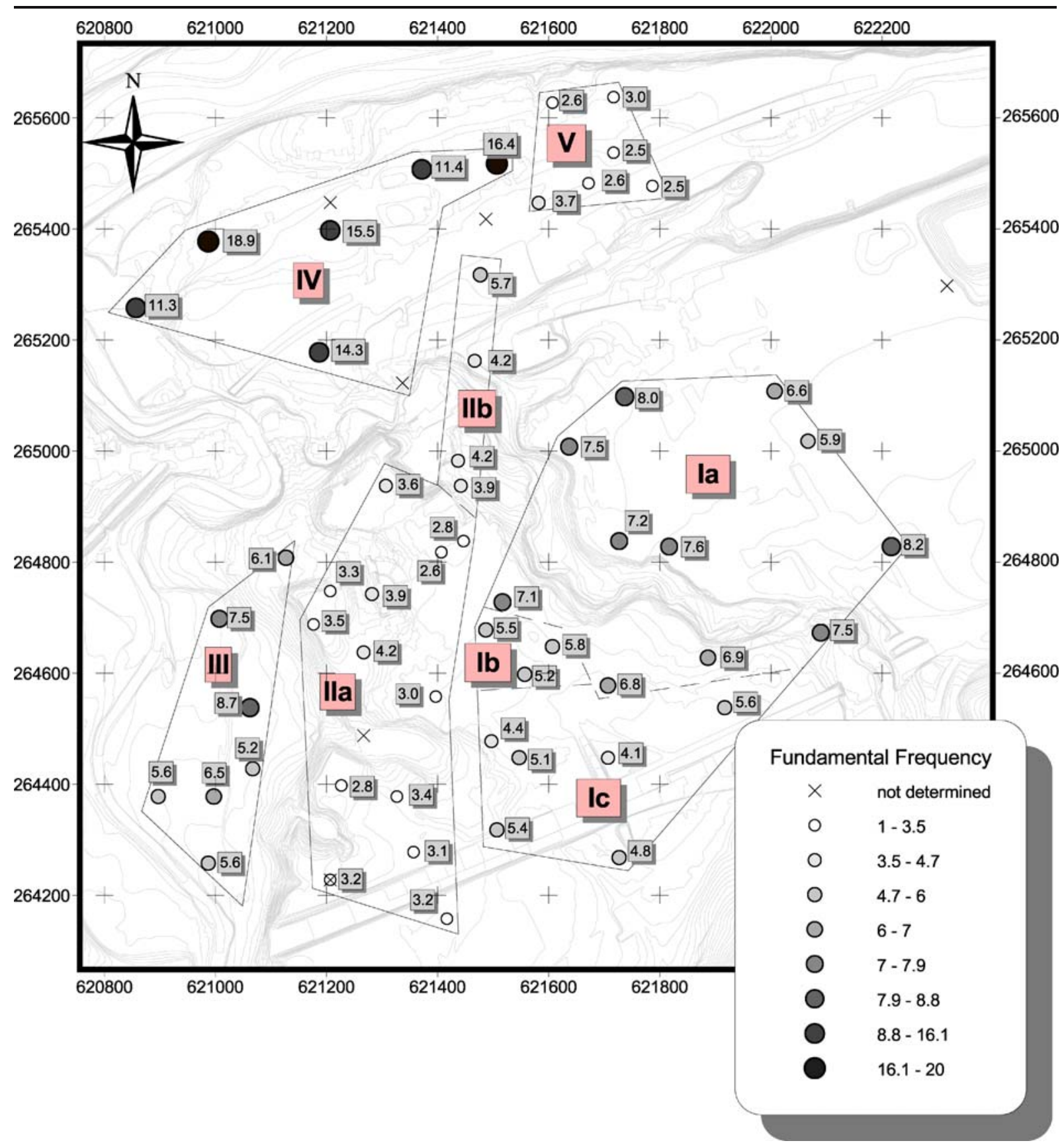

Figure 5 Distribution of fundamental frequencies and grouping into several zones characterized by similar H/V spectra and similar geology.

algorithm to find the velocity model that produces an ellipticity curve best fitting the $\mathrm{H} / \mathrm{V}$-spectrum in specified frequency intervals on the flanks of the peak.

Since there exists an infinite number of structural models leading to the same $\mathrm{H} / \mathrm{V}$-spectrum, additional information is needed to constrain the inversion (Fäh et al. 2003b). Good results can be obtained when the thickness of the geological layers are known. For some points, this information is available directly from borehole data. For some boreholes the type and depth of the uppermost geologic rock formation is specified. To gain information also for the points lacking borehole data, we proceeded in multiple steps, described in the following. 
Figure $6 \mathrm{H} / \mathrm{V}$ spectra of points in the upper city in zone IIa (upper figure) compared to spectra observed in the lower city in zone IV (lower part of the figure).
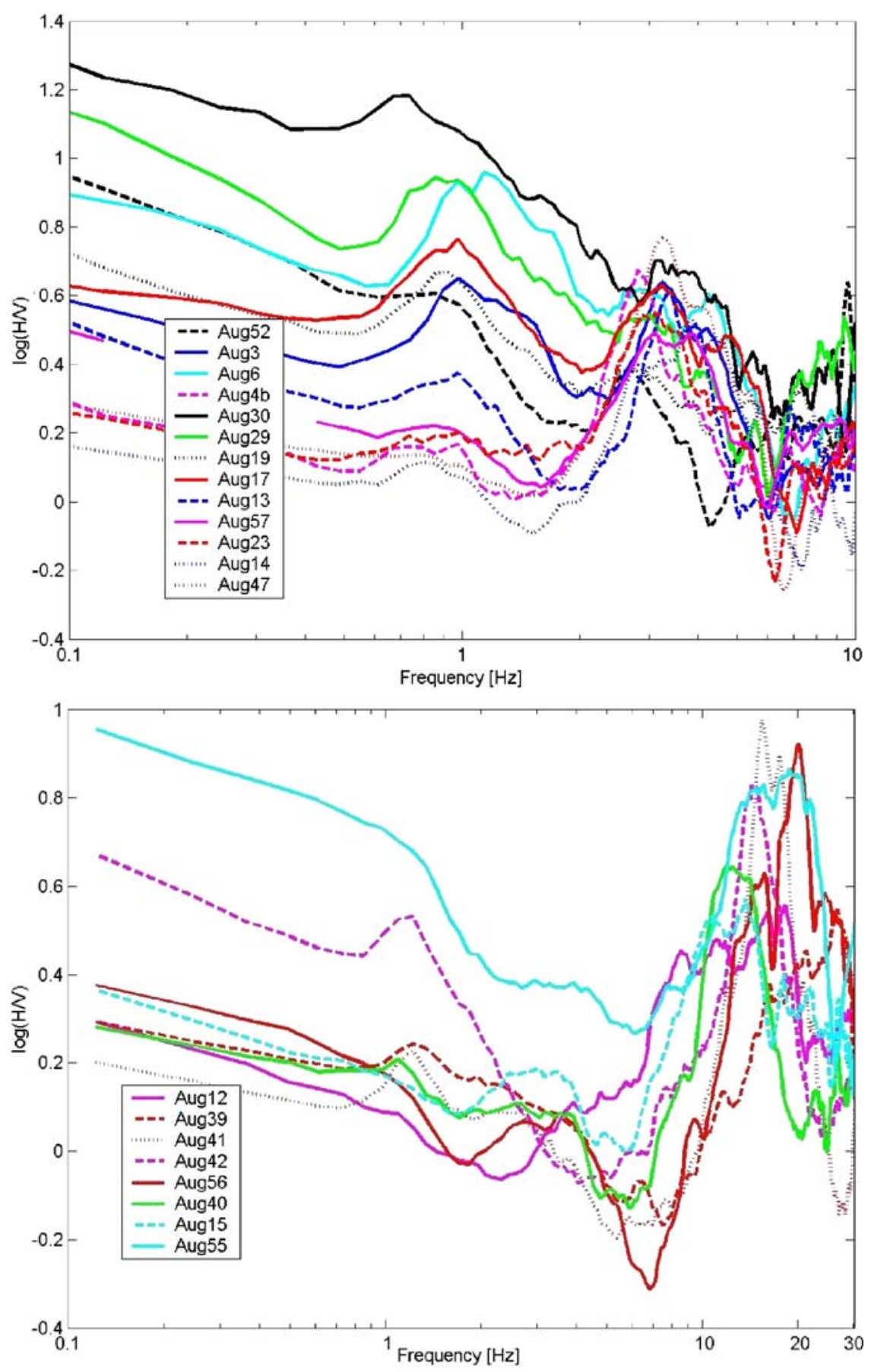

In a first step, all measuring points were selected, for which geologic information is available from a very closely located borehole and which exhibit Quaternary unconsolidated sediments ('Niederterrassenschotter') above Muschelkalk layers as uppermost rock formation. Two points met the above conditions: Aug21 and Aug45.
For both points several inversion runs were performed with varying shear-wave velocity limits for the rock formation. The obtained models showed $S$-wave velocities for the Muschelkalk roughly between 1,800 and $2,950 \mathrm{~m} / \mathrm{s}$. For all these models, synthetic $\mathrm{H} / \mathrm{V}$-curves were calculated, as proposed in Fäh et al. (2003b). They were visually compared with 
Figure 7 Shear-wave velocity (thin black lines) models for the uppermost $16 \mathrm{~m}$ of the Quaternary unconsolidated sediments ('Niederterrassenschotter') from inversion of $\mathrm{H} / \mathrm{V}$ spectra of points Aug21 and Aug45. Dotted black lines indicate the (a priori applied) velocity boundaries and the fixed depths (from borehole data) for the inversion runs. The mean velocity model (thick line) and the deduced velocity limits (dash-dotted thin lines) for the Quaternary sediments are determined in $2 \mathrm{~m}$ depth intervals. The values are listed in Table 1.

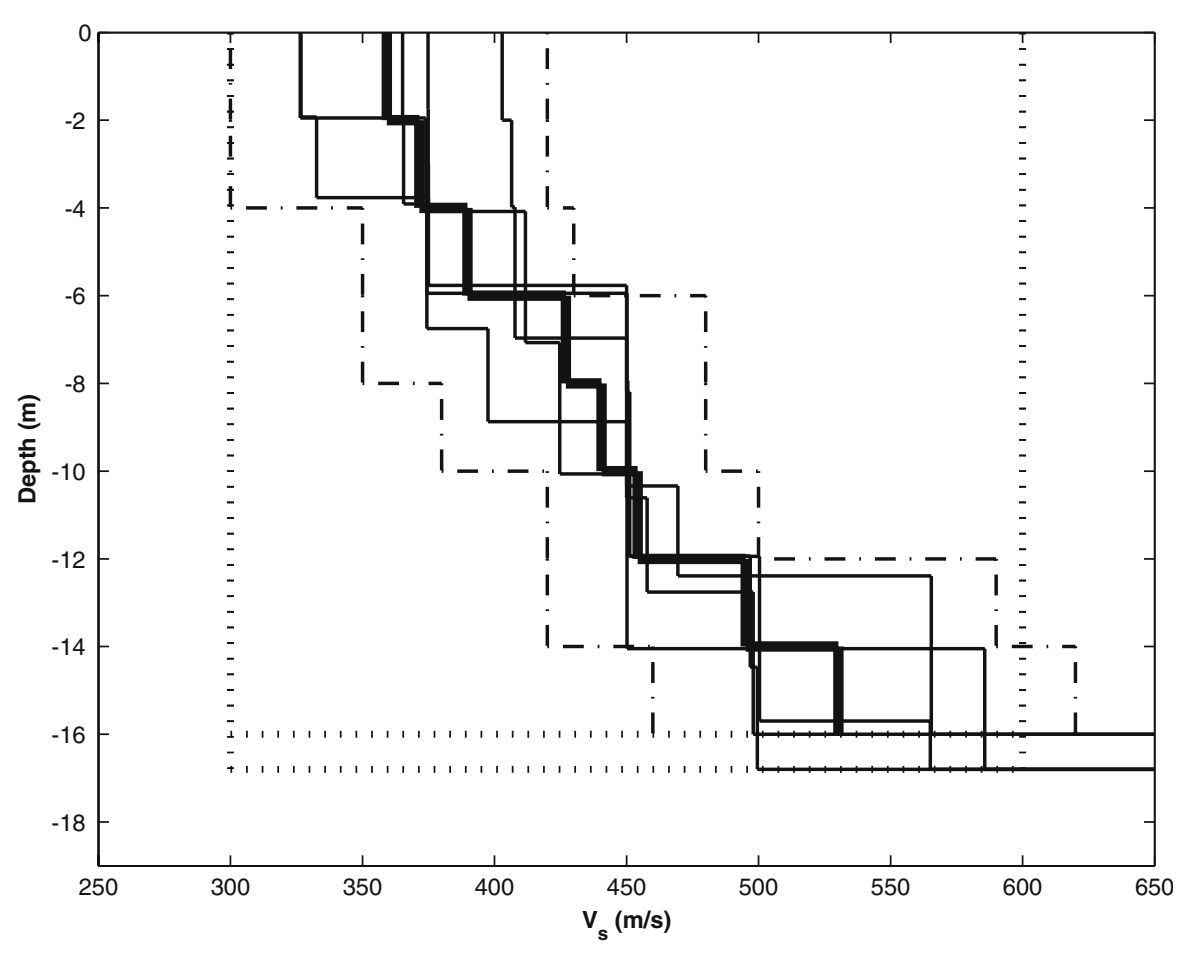

the real $\mathrm{H} / \mathrm{V}$-spectra regarding the amplitude at the $\mathrm{H} /$ $\mathrm{V}$-peak because the peak amplitude is connected with the velocity contrast. Some models were discarded, finally constraining the average $S$-wave velocity of the Muschelkalk layers to $2,100-2,900 \mathrm{~m} / \mathrm{s}$. For the Muschelkalk, a generic model was defined that has three layers $(\mathrm{vs}=1,800 \mathrm{~m} / \mathrm{s}$ for the first $10 \mathrm{~m}$, vs= $2,000 \mathrm{~m} / \mathrm{s}$ for the second $10 \mathrm{~m}$, and $\mathrm{vs}=2,400 \mathrm{~m} / \mathrm{s}$ for the third layer).

The $S$-wave velocities of the Quaternary sediments for the selected models are depicted in Figure 7. From these models we derived a generic $S$-wave velocity model of the uppermost $16 \mathrm{~m}$ of Quaternary sediments from the average value. We also estimated $S$-wave velocity boundaries for the Quaternary sediments. The minimum and maximum values for every $2 \mathrm{~m}$ depth interval were taken and about $5 \%$ of the values were subtracted or added, respectively. The resulting limits as well as the mean model are listed in Table 1 . They are considered to be valid for the socalled 'Niederterrassenschotter,' which constitutes the dominant portion of the Quaternary sediments in the whole study area. By applying the travel time based averaging scheme to this mean model, we calculated an average shear-wave velocity of $430 \mathrm{~m} / \mathrm{s}$ for the total thickness of $16 \mathrm{~m}$. In some cases the velocities in the uppermost meters might be lower than the average value if they are composed by looser material like Roman cultural layers, artificial fills etc.

To test the results of this initial step, we approximated the Quaternary sediments by a single layer with thickness $h$ and constant shear-wave velocity $V_{s}$. This velocity is estimated from the measured fundamental frequency $f_{0}$ by using the following simple formula:

$V_{s}=4 \times h \times f_{0}$

Table 1 First generic model defined by the average S-wave velocity and its limits for Quaternary unconsolidated sediments ('Niederterrassenschotter'), deduced from the inversion of $\mathrm{H} / \mathrm{V}$ spectra at site Aug21 and Aug45

\begin{tabular}{lll}
\hline Depth $(\mathrm{m})$ & vs limits $(\mathrm{m} / \mathrm{s})$ & vs mean $(\mathrm{m} / \mathrm{s})$ \\
\hline $0-2$ & $300-420$ & 360 \\
$2-4$ & $300-420$ & 370 \\
$4-6$ & $350-430$ & 390 \\
$6-8$ & $350-480$ & 430 \\
$8-10$ & $380-480$ & 440 \\
$10-12$ & $420-500$ & 450 \\
$12-14$ & $420-590$ & 500 \\
$14-16$ & $460-620$ & 530 \\
& Average: & 430 \\
\hline
\end{tabular}


Table 2 Average shearwave velocity for a single Quaternary sediment layer derived from the fundamental frequency of resonance and borehole information

\begin{tabular}{llllll}
\hline Name & $\begin{array}{l}\text { Elevation } \\
(\mathrm{m})\end{array}$ & $\begin{array}{l}\text { Base of } \\
\text { Quaternary }(\mathrm{m})\end{array}$ & $\begin{array}{l}\text { Thickness } \\
\text { Quaternary } \\
\mathrm{h}(\mathrm{m})\end{array}$ & $\begin{array}{l}\text { Fundamental } \\
\text { frequency } f_{0}(\mathrm{~Hz})\end{array}$ & $\begin{array}{l}\mathrm{vs}=4 \times \mathrm{h} \times \\
f_{0}(\mathrm{~m} / \mathrm{s})\end{array}$ \\
\hline Aug36 & 294 & 279 & 15 & 6.6 & 396 \\
Aug37 & 294 & 278 & 16 & 5.88 & 376 \\
Aug33 & 293 & 279 & 14 & 7.96 & 446 \\
Aug21 & 294 & 277 & 17 & 7.51 & 511 \\
Aug45 & 294 & 276 & 18 & 7.17 & 516 \\
Aug34 & 294 & 277 & 17 & 7.6 & 517 \\
Aug22 & 296 & 284 & 12 & 8.15 & 391 \\
& & & & Average: & 450
\end{tabular}

All the points in zone I are considered to have Muschelkalk directly lying below the Quaternary. The thickness of the Quaternary sediments is known in this area from about 30 boreholes. For each point the thickness is estimated from surrounding boreholes in distances up to $100 \mathrm{~m}$. Table 2 displays the data and the resulting shear-wave velocities. The average shear-wave velocity of $450 \mathrm{~m} / \mathrm{s}$ not only matches the average result given in Table 1 but also fits the value obtained by Kind (2002) from array measurements about $6 \mathrm{~km}$ down the Rhine valley. We will use this value later to obtain estimates of the thickness for the sites where no borehole data is available.

In the second step, the results from the previous section were used to constrain the shear-wave velocities of the gravel layer and to estimate the velocities of the Keuper layer that is found in the graben structure below Quaternary sediments. Six measuring points (Aug7, Aug9, Aug14, Aug31, Aug50 and Aug51) were chosen for this part of the inversion according to the criteria that they are all located close to a borehole showing Keuper directly below the Quaternary sediments. All points belong to zone III, with the exception
Figure 8 S-wave velocity models (thin lines) below the Quaternary obtained from inversion of $\mathrm{H} / \mathrm{V}$ spectra of selected points (Aug7, Aug9, Aug14, Aug31, Aug50 and Aug51). Note that the unconsolidated Quaternary sediments are not shown here and that the models are aligned to the top of the Keuper. Dotted black lines mark the input velocity limits of Keuper for the inversion. The thick black line indicates the average velocity model for $10 \mathrm{~m}$ depth intervals.

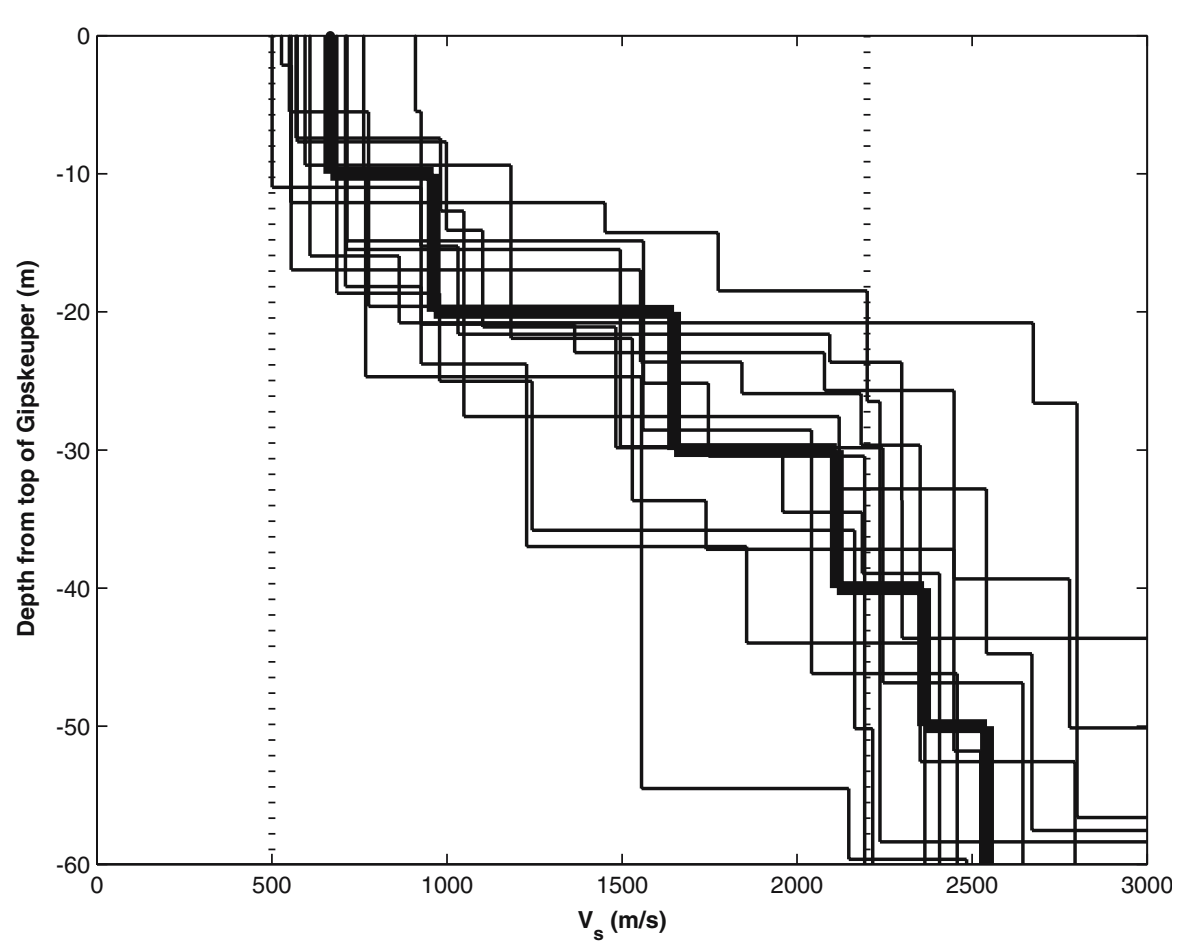


of Aug14 in the Roman theatre in the upper city of Augusta Raurica (zone IIa).

The following bounding parameters were used as input into the inversion runs:

- The $S$-wave velocity boundaries for the Quaternary sediments were set to the limits obtained in the previous section (Table 1).

- The thickness of the Quaternary sediments was taken from borehole data and fixed for most inversion runs. Small variations in the order of a few meters were allowed to account for any uncertainties in the estimation of the elevation level of the measuring points.

- Since the thickness and the $S$-wave velocities of the Keuper were completely unknown, they were allowed to vary in a rather broad range. The limits were set to a thickness of $4-100 \mathrm{~m}$ and an $S$-wave velocity of $500-2,200 \mathrm{~m} / \mathrm{s}$.

- The $S$-wave velocity limits for the Muschelkalk layers were set to $2,100-2,900 \mathrm{~m} / \mathrm{s}$ as derived in the previous section.

For each point, multiple inversion runs were performed with varying numbers of model layers for each geologic formation. We found no large variation in the inversion results for each point. Comparing all the points, we also obtained a rather homogeneous picture. The resulting $S$-wave velocity models are depicted in Figure 8. Here the Quaternary sediments are not shown and the models have been aligned to the top of the Keuper. This highlights the common features of the Keuper velocity structures.

Most important is the fact that the uppermost 5$20 \mathrm{~m}$ of the Keuper appear to have shear-wave velocities between 500 and $800 \mathrm{~m} / \mathrm{s}$. The average velocity in this interval is $630 \mathrm{~m} / \mathrm{s}$, which is comparable to the velocities of the Quaternary sediments. The base of the Keuper beds is considered to be around the point where the velocity increases above $2,200 \mathrm{~m} / \mathrm{s}$, marked in Figure 8 by a vertical dashed black line.

An average model with $10 \mathrm{~m}$ depth intervals was estimated for $60 \mathrm{~m}$ down from the top of the Keuper layer, and represented by the thick line in Figure 8 . The average model displays a rather smooth increase in velocity and thus masks the sudden jump in velocity present in each separate model. In order to account for this artefact in the velocity model, a generic model is proposed for the Keuper and given in Table 3.
Table 3 Generic model for the Keuper taking into account the sudden jump in velocity present in each separate model in Figure 8 . The P-wave velocities $v_{\mathrm{p}}$ are estimated from measurements for similar ground conditions (Kind 2002)

\begin{tabular}{lll}
\hline Depth from base of Quaternary $(\mathrm{m})$ & $\mathrm{vp}(\mathrm{m} / \mathrm{s})$ & $\mathrm{vs}(\mathrm{m} / \mathrm{s})$ \\
\hline $0-10$ & 2,000 & 580 \\
$10-17$ & 2,100 & 600 \\
$17-18$ & 2,300 & 650 \\
$19-24$ & 2,700 & 900 \\
$24-35$ & 3,100 & 1,250 \\
$35-40$ & 3,100 & 1,500 \\
\hline
\end{tabular}

\section{Mapping the top of geophysical bedrock}

The results of the previous chapter can be used to estimate the surface of the seismic velocity contrast, which we call 'geophysical bedrock.' For some parts of the study area we know from boreholes, that the Muschelkalk constitutes the geophysical bedrock right below the Quaternary sediments. In other parts Keuper sediments are documented below the Quaternary. In these parts it cannot be entirely distinguished if the geophysical bedrock represents the top of the Muschelkalk underlying the Keuper sediments or if some layers inside the Keuper sediments themselves act as the geophysical bedrock - depending of the state of weathering of these layers.

For the sites with Quaternary sediments directly above the Muschelkalk, the thickness $h$ of the Quaternary sediments can be estimated from the measured fundamental frequency $f_{0}$ and the average shear-wave velocity $V_{s}=450 \mathrm{~m} / \mathrm{s}$ using:

$h=\frac{V_{s}}{4 \times f_{0}}$.

At sites where a second soft layer representing the Keuper sediments is present, we use the travel-time based velocity averaging to estimate the total thickness of soft sediments. The fundamental frequency $f_{0}$ is related to the thickness of the Quaternary $\left(h_{1}\right)$ and the Keuper sediments $\left(h_{2}\right)$ and the respective shearwave velocities $v_{1}$ and $v_{2}$ by the following formula:

$f_{0}=\frac{1}{4 \times\left(\frac{h_{1}}{v_{1}}+\frac{h_{2}}{v_{2}}\right)}$.

For the average shear-wave velocity $v_{2}$ of weathered Keuper, a value of $630 \mathrm{~m} / \mathrm{s}$ is taken. If the thickness of 
the Quaternary sediments is given, we can solve this equation for the thickness of the Keuper layer $h_{2}$ as

$h_{2}=v_{2} \times\left(\frac{1}{4 \times f_{0}}-\frac{h_{1}}{v_{1}}\right)$.

All the information from the measurement points of the five zones and the borehole data are analysed and put together to create a map of the top of the geophysical bedrock. The values were interpolated to a $10 \mathrm{~m}$ grid (Figure 9). The locations of measurement points used for the interpolation are marked with triangles; the locations of used boreholes are marked with circles. The interpolation is also performed for parts (especially the corners) where information is very sparse or not available at all. Accordingly, these parts have to be considered not reliable. The blue line in Figure 9 outlines the area inside which the interpolation is considered valid. The map shows the main fault crossing the study area. The dashed black line highlights its approximate position.

As a second surface we mapped the boundary between the Quaternary and the Keuper sediments. This interface is documented in several boreholes and from these values the surface is interpolated using the same parameters as for the interpolation of the top of the geophysical bedrock.

The uncertainties in the depth calculations result from the uncertainty in the determination of the fundamental frequency $f_{0}$ and the uncertainty in the $S$ wave velocity structure. The uncertainties resulting from the picking of the fundamental frequency and from the improper knowledge of the $S$-wave velocity model both have the same order of magnitude. They can each influence the calculated depth to the geophysical bedrock by about $10 \%-20 \%$. The uncertainty in the obtained 3D surface is highest in the regions where Keuper sediments are present (i.e., zones II and III). The uncertainty is lowest for the area where Quaternary sediments are directly lying on top of the Muschelkalk.

\section{Modelling of possible amplification effects}

To investigate possible earthquake scenarios, we performed ground motion simulations. All $S$-wave velocity models obtained with the inversion procedure are first used to estimate possible amplification of seismic waves in 1D structural models. From the inversion of selected measuring points, generic $S$ wave velocities were determined for the unconsolidated Quaternary gravels, the Keuper and the Muschelkalk. With these velocities we constructed a 3D model to analyse possible 3D amplification effects in the study area. Due to the presence of the river terrace and the buried graben structure, 3D effects are expected, in particular in the upper city.

\section{$1 D$ modelling}

The modal summation for the SH and PSV case is applied to quantify amplification in the 1D case (Panza 1985; Panza and Suhadolc 1987; Florsch et al. 1991). Amplification effects depend on the source characteristics. The most important factors are the source depth, the distance, the orientation and mechanism of the source. These are accounted for by numerical modeling of multiple point sources. The double-couple sources are located at randomly selected distances (between 20 and $50 \mathrm{~km}$ ), source depths (between 2 and $20 \mathrm{~km}$ ), angles between the strike of the fault and the epicenter-station line (between 0 and $360^{\circ}$ ), fault dips (between 40 and $90^{\circ}$ ), fault rakes (between 0 and $360^{\circ}$ ), and source durations (between 0.05 and $0.2^{\circ} \mathrm{s}$ ). In total 512 sets of randomly selected source parameter combinations are selected but kept stable for all models calculated. Synthetic seismograms are calculated for the soft-sediment sites and for a reference rock site using the same sources. The reference bedrock model used represents a model derived from the geophysical settings in the Tabular Jura with the Quaternary removed. A slight $S$-wave velocity gradient in the top $30 \mathrm{~m}$ of material, increasing from $1,000 \mathrm{~m} / \mathrm{s}$ to $2,000 \mathrm{~m} / \mathrm{s}$ simulates a realistic situation at a reference station. $v_{\mathrm{s}, 30}$ is around $1,500 \mathrm{~m} / \mathrm{s}$.

The modeled ground motion is used to quantify the seismic ground motion amplification with respect to the reference bedrock. The amplification is expressed in terms of spectral amplification SA(site)/SA(bedrock) for $5 \%$ damping. The numerical simulation for one seismic source yields spectral amplification for

Figure 9 Surface of the top of geophysical bedrock. Map interpolated both from calculated values and borehole data. The points where information was used are given. The thick blue line gives the boundary of valid interpolation. The dashed black line indicates the position of the main fault in the study area. All values are given in meters above sea-level. 


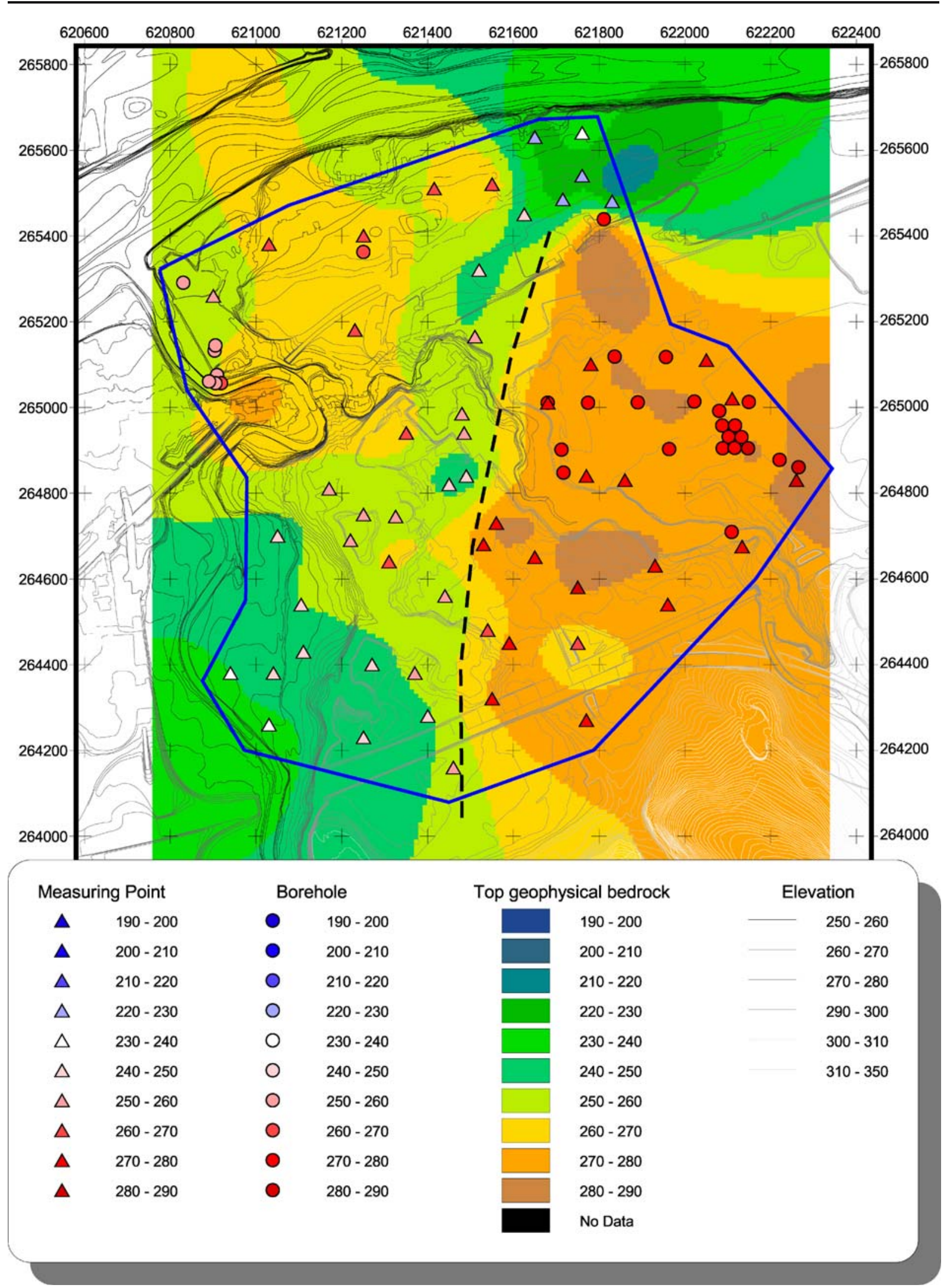


Figure 10 Example of the calculation of spectral amplification calculated for 512 different sources on one sample model (site Aug60). The middle plot is showing all results as thin black lines. The gray area marks the minimum and maximum range and the dashed thick line gives the mean amplification value. The vertical solid lines mark the cross sections at which the distribution of the spectral amplifications is given using histograms. The range for the estimated $f_{0 \text {,mea }}$ using the $\mathrm{H} / \mathrm{V}$ methodology is indicated by the circle and the two arrows at the top of the figure. Dashed lines in the histogram plots indicate the mean value of the amplification distributions given.
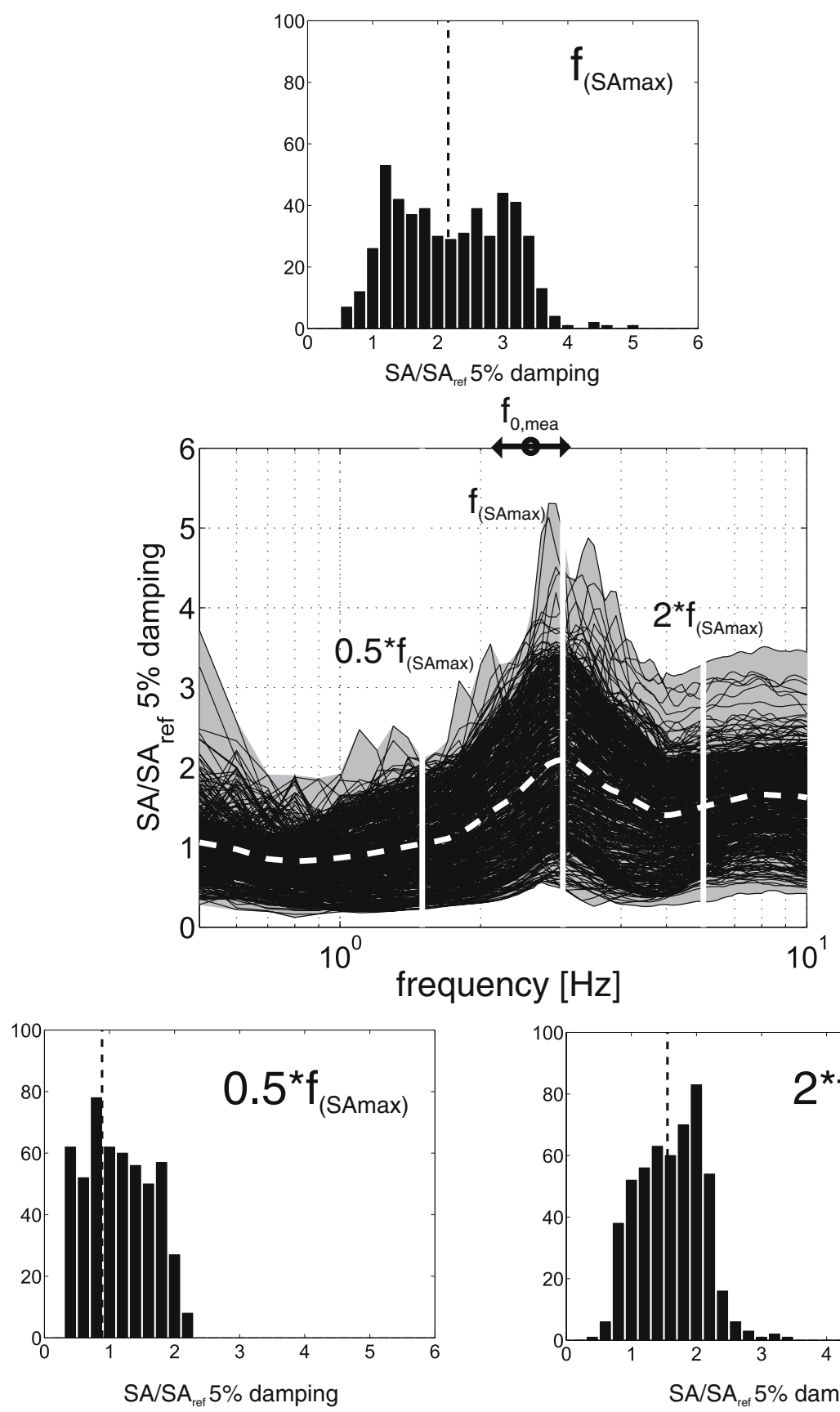

$5 \%$ damping relative to bedrock (reference model). From the spectral amplification obtained for the 512 different seismic sources, mean and maximum amplification are obtained. Amplification is computed for the total horizontal and the vertical component. In order to get an idea of the influence of the source characteristics on the calculated amplification, Figure 10 shows the results of all 512 sources in one plot.
Note the broad range of amplification values due to the use of the different sources. The reasons are the differences in the composition and input angles of the wave field. The three smaller histograms in Figure 10 give the distribution of the amplification values at three different frequency values: at the frequency of maximum amplification $f_{\mathrm{SA} \text {, max }}$ in the frequency range between 0.5 and $10 \mathrm{~Hz}$, at half this frequency 

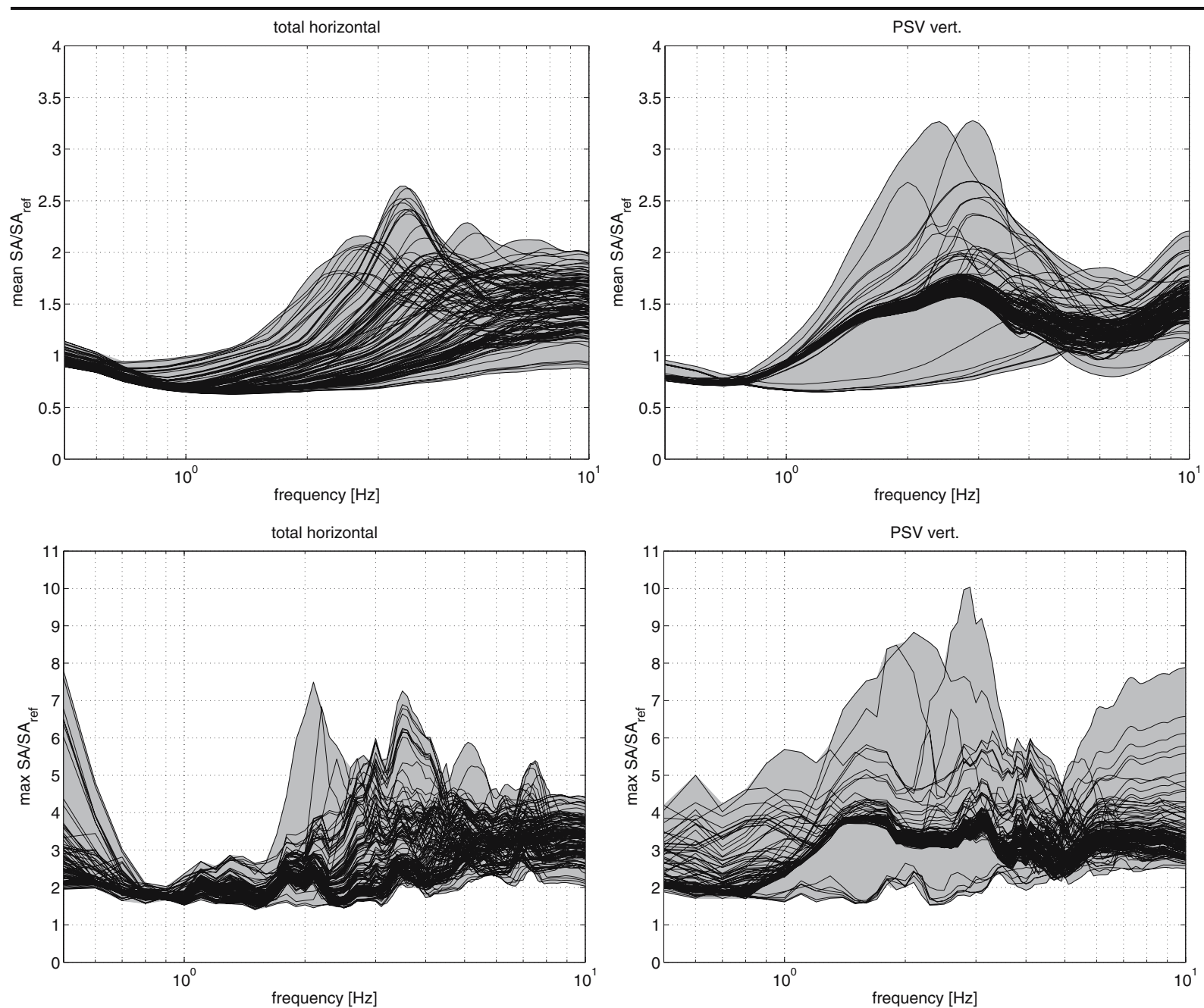

Figure 11 Mean (upper row) and maximum (lower row) spectral amplification at 5\% damping for all models derived from the ambient vibration site points in Augusta Raurica for the total horizontal (left row) and the vertical (right row) component.

$\left(0.5 \times f_{\mathrm{SA}, \max }\right)$, and at two times the frequency of maximum amplification $\left(2 \times f_{\mathrm{SA}, \max }\right)$. While a big number of sources lead to amplifications around the mean value, 'maximum amplification' is an extreme value often only reached by one single source. In Figure 10 the mean amplification at $f_{\mathrm{SA}, \max }$ is about two while the maximum value lies above an amplification factor of five. This difference can be interpreted as a measure of aleatory uncertainty in the ground motion calculation procedure due to the unknown source characteristics of future earthquakes. As expected, maximum amplification occurs around the fundamental frequency of resonance $f_{0}$ of the soft sediments over rock. The estimated range of fundamental frequency of resonance using $\mathrm{H} / \mathrm{V}$ methodology is therefore given for comparison $\left(f_{0}\right.$, mea).
A total of 147 models from 38 different site points are used to calculate amplification for sites in Augusta Raurica. The parameters of the ground models for the soft sediment sites are derived from inversions of $\mathrm{H} / \mathrm{V}$ ambient vibration analysis. Figure 11 gives the maximum and mean spectral amplification for all these models.

Sub samples of models can be selected from this group based on given ranges of parameters. Here the fundamental frequency of resonance and the shearwave velocity of the uppermost rock layer found for the different zones have been used as selection criteria.

Models are first selected based on the fundamental frequency of resonance, and in a second step based on the shear-wave velocity of the uppermost rock layer, which had to be above $2,000 \mathrm{~m} / \mathrm{s}$. Two different 

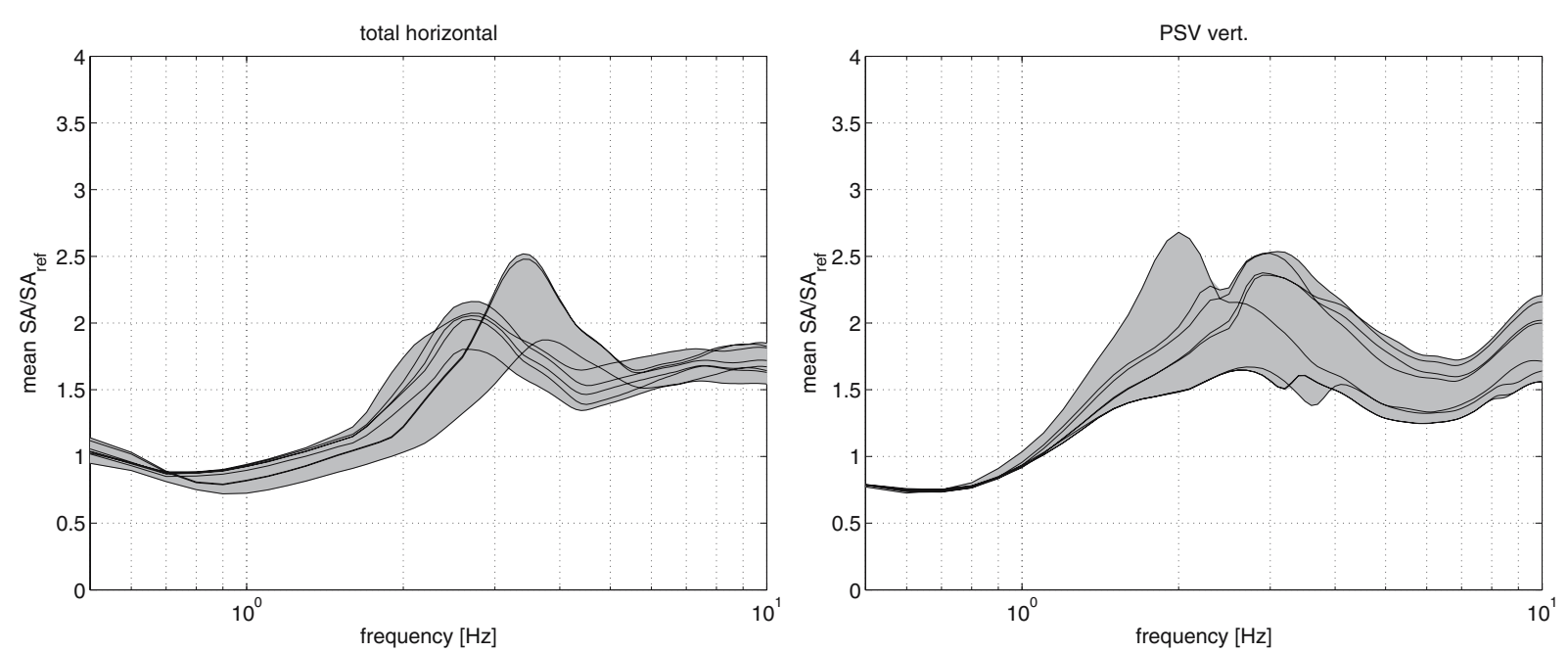

Figure 12 Mean spectral amplification at 5\% damping for the selected models with $f_{0}$ between 2 and $5 \mathrm{~Hz}$ (upper city).

frequency ranges for $f_{0}$ have been used: 2 to $5 \mathrm{~Hz}$ (zone $\mathrm{V}$ and II, upper city), and the models with $f_{0}>$ $10 \mathrm{~Hz}$ (zone IV, lower city). The spectral amplification is given for all models in the frequency range between 0.5 and $10 \mathrm{~Hz}$, which is the range of engineering interest.

\section{Frequency range for $f_{0}$ between 2 to $5 \mathrm{~Hz}$ (zone $\mathrm{V}$ and II, upper city)}

Sixty-one models can be selected based on the fundamental frequency range of 2 to $5 \mathrm{~Hz}$ alone, eight models remain in the selection when the rock

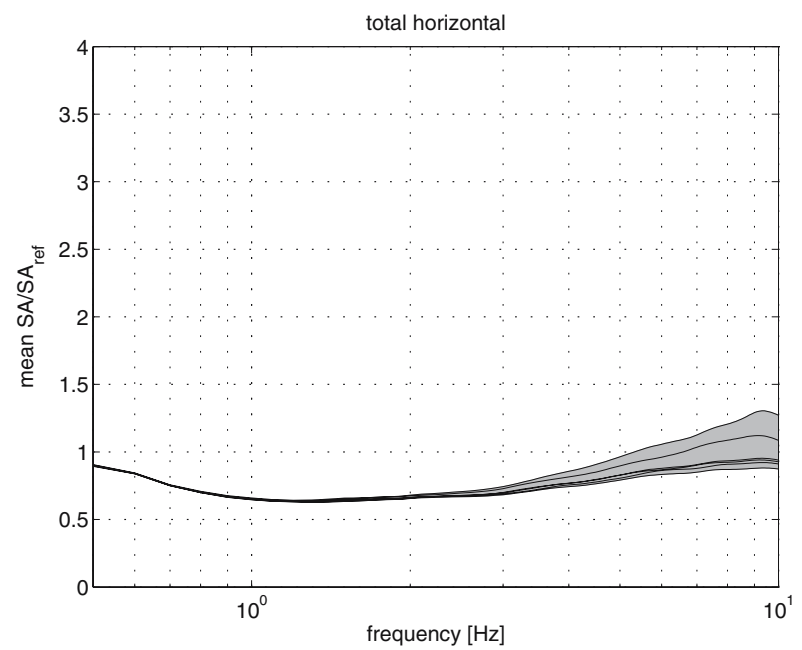

velocity criterion is also used. The amplifications are given in Figure 12.

\section{Frequency $f_{0}$ above $10 \mathrm{~Hz}$ (zone IV, lower city)}

Six models can be selected based on the fundamental frequency to be above $10 \mathrm{~Hz}$. This selection remains unaffected by the additional condition for the rock velocity. Figure 13 shows the mean amplification for the total horizontal and the vertical component.

When comparing the results obtained for the upper city and for lower city, it becomes evident, that

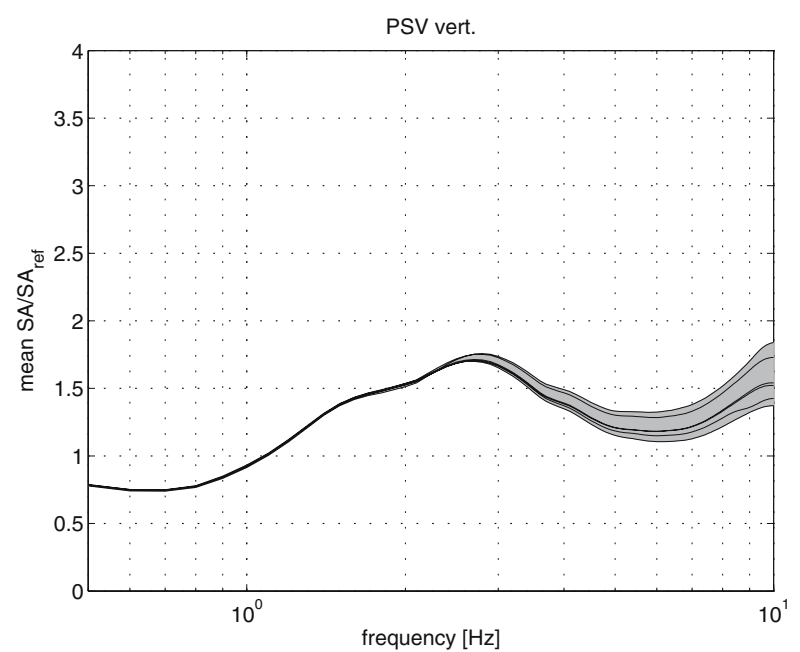

Figure 13 Mean amplification for the ground models having $f_{0}>10 \mathrm{~Hz}$ (lower city). 
expected damage in the upper city is larger than in the lower city. A factor of about 2.5 to 3 difference between the respective amplification effects would result in a difference of about one unit in macroseismic intensities.

\section{D modelling}

In the upper city we expect 3D effects due to the topography of the river terrace and of the graben structure. For the Quaternary sediments, we chose the generic model determined from measurements as specified in Table 1. The generic model of the Keuper layer is given in Table 3. The depth of the bedrock interface given in Figure 9 is slightly adjusted so that the fundamental frequencies of resonance of the model remain within the error limits of the measured frequencies at all sites.

We select vertical incidence of seismic waves. This constitutes the worst case since the energy is most efficiently transported into the soft sediments. The incident waves correspond to the $\mathrm{Mw}=5.9$ Athens earthquake. The incident wavefield is computed by using the kinematic PEXT method (Zahradník and

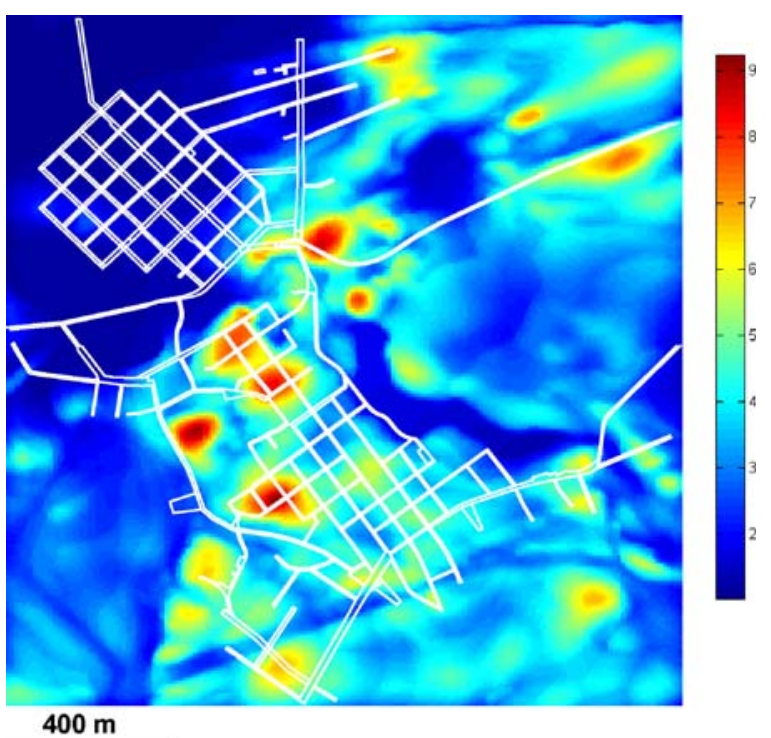

Figure 14 Computed maximum spectral amplification in the frequency band between 0.5 and $10 \mathrm{~Hz}$ for a hypothetical earthquake of magnitude $\mathrm{Mw}=5.9$
Figure 15 Mean and maximum spectral amplifications in zones IIa, IIb, and IV computed for a vertical incidence of S-waves from a hypothetical earthquake of magnitude $\mathrm{Mw}=5.9$.

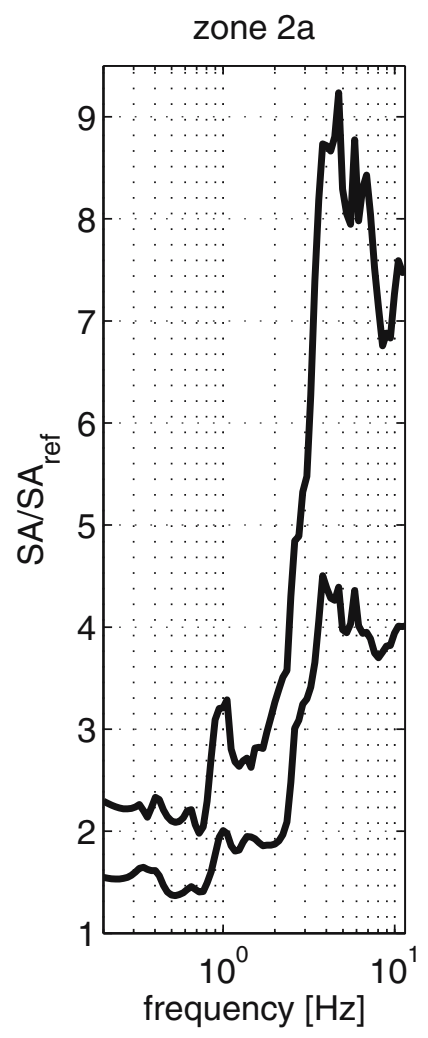

zone $2 \mathrm{~b}$

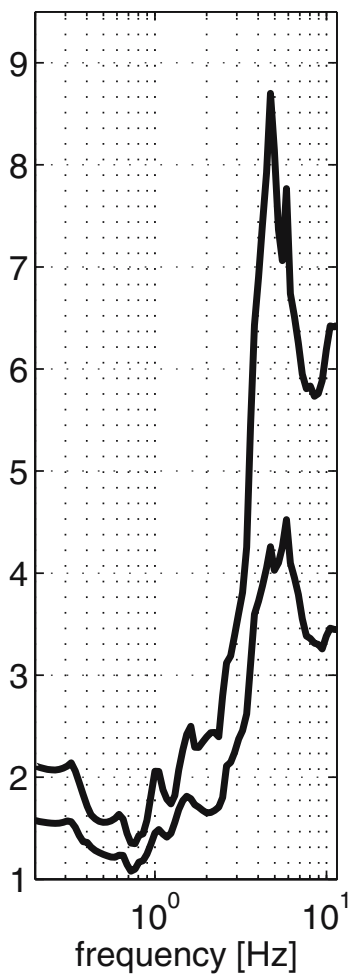

zone 4

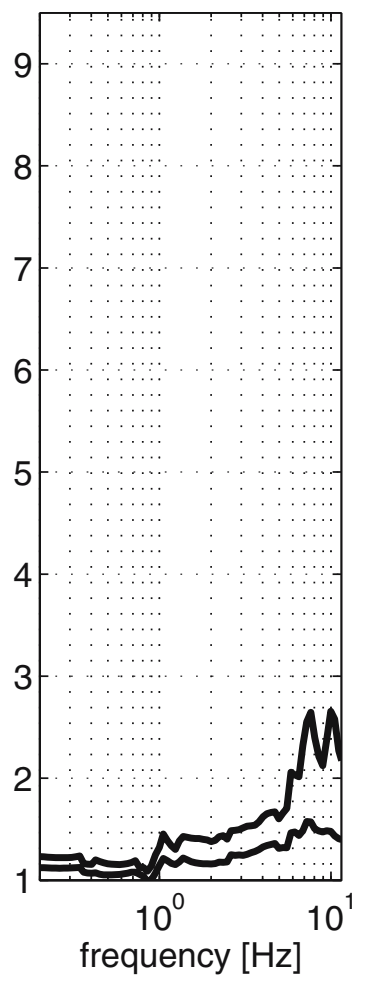


Tselentis 2002). The PEXT method models finiteextent source complexities by stochastic PErturbation and EXtrapolation of the deterministic wavefield. The method uses complete Green's functions computed by the Discrete Wave number Method (DWN, Bouchon 1981; Coutant 1989). The seismic source has the following parameters: length and width $L=10 \mathrm{~km}, W$ $=8 \mathrm{~km}$, source composed of $5 \times 5=25$ subevents, each subevent with the slip duration of $0.57 \mathrm{~s}$, and average slip of $0.059 \mathrm{~m}$. The 3D modelling is performed using the 3D finite difference method (Opršal et al. 2002; 2004; 2005).

The results are given in Figures 14 and 15 . Figure 14 shows the maximum amplification for 5\% damping observed at all places within the frequency band 0.5 to $10 \mathrm{~Hz}$. Maximum amplification occurs close to the fundamental frequency of resonance and reaches values up to nine. Such large amplifications are caused by a combined effect of the topography and the graben structure. Figure 15 displays the mean and maximum amplifications in zones IIa and IIb (upper city) and slightly modified zone IV (lower city) caused by this hypothetical earthquake. The variability of amplification is considerable and is varying over short distances. The mean values of the amplification in zone IIa has typical spectral amplification around 1.5-2 for frequencies lower than $2.5 \mathrm{~Hz}$, and amplification of about four for frequencies above $4 \mathrm{~Hz}$. Zone IIb shows an amplification peak of 4.5 around 4 to $6 \mathrm{~Hz}$. Zone IV shows lower mean amplifications of 1 to 1.5. Amplifications are much larger than for the $1 \mathrm{D}$ simulations due to the $3 \mathrm{D}$ effects and the assumed vertical incidence of seismic waves.

\section{Conclusions}

Ambient noise data was recorded in the area of the Roman city Augusta Raurica. The resulting dense mesh of recording sites allowed for a detailed mapping of the fundamental frequency of resonance, which was extracted from $\mathrm{H} / \mathrm{V}$ polarization spectra. The spatial variability of the fundamental frequency is high with values ranging from roughly $2-20 \mathrm{~Hz}$. This high variability is due to the fact, that the fundamental frequency in the study area is mainly controlled by the thickness of the Quaternary sediments and a Keuper graben. The study area was divided in five zones according to their fundamental frequencies, the overall shape of their $\mathrm{H} / \mathrm{V}$-spectra and the geology.

Zones with fundamental frequencies close to the eigenfrequencies of buildings are critical zones in terms of earthquake hazard. For large Roman buildings eigenfrequencies of $1-3 \mathrm{~Hz}$ are expected. For the common Roman two-story buildings we expect eigenfrequencies of 6-8 Hz.

Zone II of our study comprises the upper city of Augusta Raurica, including most of the larger buildings like the main forum, the theatre and the amphitheatre. The upper city is located on a river terrace and partly lies on top of the graben structure. This part shows most of the features indicating earthquake damages. The lower city is built in lower parts of the Rhine valley on Quaternary gravel layers of about $10 \mathrm{~m}$ thickness. Here no damages pointing to an earthquake have been found so far. While in the upper part of the city amplification occurs in the frequency band of building resonance $(2-8 \mathrm{~Hz})$, the amplifications in the lower city occur at frequencies much higher than the buildings resonance. It is therefore evident that site effects play a major role in the upper city.

From numerical modelling we estimated ground motion amplifications as a function of frequency for the different zones. From 1D modelling we estimate a difference in spectral amplification of about a factor of 2.5 to 3 between upper and lower city in the frequency band $2-10 \mathrm{~Hz}$. This corresponds approximately to a difference in macroseismic intensity of one unit. 3D modelling showed a large variability of ground motion within very close distance in the upper city. The maximum amplification reaches values up to a factor 9 which is due to 3D effects and the choice of using vertically incident waves.

Paleoseismological findings in the area of Basel and the surrounding regions provide no hints to a large earthquake in the third century (Becker et al. 2002, 2004; Ferry et al. 2003; Meghraoui et al. 2001). However paleoseismology allows only the recognition of very strong earthquakes that caused secondary effects in a wide area. The seismological investigations revealed a geological structure that can cause very large amplifications due to a combination of topographical and site effects. If we assume that an earthquake caused at least part of the identified damage in Augusta Raurica, we have to assign to this event a magnitude Mw of about 6.0 or lower, that 
is much smaller than the value of 6.9 that is actually in the Swiss earthquake catalogue ECOS02 (Fäh et al. 2003a). The earthquake source of this event must then be very close to the site of Augusta Raurica.

The archaeological investigations do not draw a conclusive picture and it could not be proved that all features of possible destruction date to the same event. Furthermore, there may be explanations for a number of the damage features observed in Augusta Raurica other than an earthquake. Examples could be a possible inundation in the southern part of the city, or stone robbery leading to instabilities in the case of the theatre. However, another explanation for the buried human bodies could not be found.

Acknowledgments This research has been funded by the Swiss National Science Foundation (Nr. 1214-63542.00; Nr. 100012-105352). We thank G.F. Panza and the Seismology Group of the Trieste University for the use of the spectral part of the Rayleigh waves program. We would like to thank F. Galadini and an unknown reviewer for their input.

\section{References}

Becker A, Davenport CA, Giardini D (2002) Paleoseismicity studies on end-Pleistocene and Holocene lake deposits around Basle, Switzerland. Geophys J Int 149:659-778

Becker A, Ferry M, Monecke K, Schnellmann M, Giardini D (2004) Multiarchive paleoseismic record of late Pleistocene and Holocene strong earthquakes in Switzerland. Tectonophysics 400:153-177

Bender H (1975) Archäologische Untersuchungen zur Ausgrabung Augst-Kurzenbettli. Ein Beitrag zur Erforschung der römischen Rasthäuser. Antiqua 4 (Frauenfeld 1975) Taf. 1,1

Bouchon M (1981) A simple method to calculate Green's functions for elastic layered media. Bull Seismol Soc Am 71:959-971

Coutant O (1989) Programme de simulation numerique AXITRA. Rapport LGIT, Universite Joseph Fourier, Grenoble, France

Fäh D, Kind F, Giardini D (2001) A theoretical investigation of average H/V ratios. Geophys J Int 145:535-549

Fäh D, Giardini D, Bay F, Bernardi F, Braunmiller J, Deichmann N, Furrer M, Gantner L, Gisler M, Isenegger D, Jimenez MJ, Kästli P, Koglin R, Masciadri V, Rutz M, Scheidegger C, Schibler R, Schorlemmer D, SchwarzZanetti G, Steimen S, Sellami S, Wiemer S, Wössner J (2003a) Earthquake catalogue of Switzerland (ECOS) and the related macroseismic database. Eclogae Geol Helv 96:219-236
Fäh D, Kind F, Giardini D (2003b) Inversion of local S-wave velocity structures from average $\mathrm{H} / \mathrm{V}$ ratios, and their use for the estimation of site-effects. J Seismol 7:449-467

Ferry M, Meghraoui M, Delouis B, Giardini D (2003) Evidence for Holocene paleoseismicity along the Basel-Rheinach active normal fault (Switzerland): a seismic source for the 1356 earthquake in the Upper Rhine graben. Geophys J Int 160(2):554-572

Florsch N, Fäh D, Suhadolc P, Panza GF (1991) Complete synthetic seismograms for high frequency multimode $\mathrm{SH}-$ waves. Pure Appl Geophys 136:529-560

Kind F (2002) Development of microzonation methods: application to dissertation no. 14548. ETH Zurich, 2002, Basle, Switzerland

Meghraoui M, Delouis B, Ferry M, Giardini D, Huggenberger P, Spottke I, Granet M (2001) Active normal faulting in the Upper Rhine graben and paleoseismic identification of the 1356 Basel earthquake. Science 293:2070-2073

Opršal I, Brokešová J, Fäh D, Giardini D (2002) 3D hybrid rayFD and DWN-FD seismic modeling for simple models containing complex local structures. Stud Geophys Geod 46:711-730

Opršal I, Zahradník J, Serpetsidaki A, Tselenits G-A (2004) 3D hybrid simulation of the source and site effects during the 1999 Athens earthquake. In: Proc. of 13th world conference on earthquake engineering, Vancouver, British Columbia, Canada, 1-6 August 2004, Paper no. 3337

Opršal I, Fäh D, Mai M, Giardini D (2005) Deterministic earthquake scenario for the Basel area - simulating strong motion and site effects for Basel, Switzerland. J Geophys Res 110, B04305, http://dx.doi.org/10.1029/ 2004JB003188

Panza GF (1985) Synthetic seismograms: The Rayleigh waves modal summation. J Geophys 58:125-145

Panza GF, Suhadolc P (1987) Complete strong motion synthetics. In: Bolt BA (ed) Seismic strong motion synthetics. Computational techniques, vol 4. Academic, Orlando, pp 153-204

Ripperger J, Fäh D (2003) Records of earthquakes, battles, and reconstructions in Augusta Raurica: an archeological and seismological research project. Second-year report, Schweizerischer Erdbebendienst ETH Zürich, 11 Nov 2003

Schibler J, und Furger AR (1988) Die Tierknochenfunde aus Augusta Raurica (Grabungen 1955-1974). Forsch. Augst 9 (Augst 1988), Abb. 122

Spottke I (2002) Widerstandsmesssungen im Gebiet der Römerstadt Augusta Raurica. Interner Bericht, Angewandte und Umweltgeologie Universität Basel, 6.5.2002

Wössner J (2002) Records of earthquakes, battles and reconstructions in Augusta Raurica: an archaeological and seismological research project - Zwischenbericht, Internal Report of the Swiss Seismological Service, ETH Zurich, 2002

Zahradník J, Tselentis G-A (2002) Modeling strong-motion accelerograms by PEXT method, application to the Athens 1999 earthquake, In Proc. of XXVIII General Assembly of the European Seismological Commission, Genoa, 1-6 Sep. 2002 (CD-ROM), or http://www.seis30.karlov.mff.cuni.cz 